\title{
A gestão do Sistema Único de Assistência Social (SUAS): uma discussão sobre os eixos estruturantes
}

\section{The management of the Unified Social Assistance System (SUAS): a discussion of the structural axes}

\author{
Angela Maria Moura Costa Prates*
}

Resumo: O presente artigo tem como objetivo discutir a gestão do Sistema Único de Assistência Social (SUAS), considerando os seus eixos estruturantes e os desafios para a sua implementação na gestão pública. Trata-se de uma pesquisa bibliográfica tendo por base a Política Nacional de Assistência Social (PNAS) e autores que discutem os princípios democráticos da gestão pública. Percebemos que o atual sistema, no marco da legalidade, rompe com os aspectos tuteladores historicamente presentes na política e inova uma perspectiva de direito de cidadania. A gestão do SUAS em acordo com as normativas legais pode produzir o efeito de romper com os estigmas conservadores, históricos na Política de Assistência Social, e construir uma política de fato pública, direito do cidadão e dever do Estado.

Palavras-chave: Assistência Social - Sistema Único - Eixos Estruturantes.

\begin{abstract}
This article aims to reflect on the structuring bases of the Unified System Social Assistance (SUAS) and the challenges to its implementation in daily practice of public management. It is grounded in a literature references that discuss the system, and documentary research is about the same. We realize that the current system within the framework of legality, disrupts aspects guardianship historically present in the Politics of Social Welfare and innovative perspective of citizenship rights and this challenges the public administration in order to understand the social assistance as a state policy and not government. But we must beware of the tendency focus that imposes neoliberal public management and influencing on Social Assistance Policy.
\end{abstract}

Keywords: Social Assistance - Unified System - Structuring Bases

Recebido em: 02/05/2014. Aceito em: 09/12/2014. 


\section{Introdução}

Este artigo tem como objetivo discutir a gestão do Sistema Único de Assistência Social (SUAS), considerando os seus eixos estruturantes e os desafios para a sua implementação na gestão pública.Este sistema foi organizado para materializar o conteúdo da Lei Orgânica de Assistência Social (LOAS) no Brasil, na perspectiva de tornar a Assistência Social uma política pública de direitos. Parte das discussões deste trabalho estão contidas na dissertação de mestrado em Ciências Sociais Aplicadas intitulada "Os impasses para a implementação do Sistema Único de Assistência Social no Município de Guarapuava - PR" defendida em 2011 na Universidade Estadual de Ponta Grossa (UEPG). Portanto, trata-se de uma pesquisa bibliográfica, com base na Política Nacional de Assistência Social (PNAS) e os eixos estruturantes do SUAS e autores que analisam os princípios da gestão pública numa perspectiva democrática. Para isso agrupamos os eixos em sub-temas, como: a descentralização político-administrativa que prevê a prestação de serviços socioassistenciais de forma territorializada, tendo a família como foco central de sua atenção; o financiamento e a política de recursos humanos, e quais são suportes fundamentais para a prestação de serviços socioassistenciais; a informação, o monitoramento e a avaliação como importantes ferramentas para a gestão da política; os conseIhos de assistência social nas três esferas de governo e o desafio da participação popular como exercício do controle social, que faz com que haja a necessidade de discutir novas bases para a relação entre estado e sociedade civil, numa relação democrática e participativa.

O Sistema Único de Assistência Social (SUAS) foi mais um passo no processo de implementação da Política Nacional de Assistência Social (PNAS), constituindo-se os dois instrumentos normativos mais recentes no processo de avanço da Assistência Social. Ele foi elaborado com o intuito de dar andamento ao processo de consolidação da Assistência Social enquanto política pública de direitos e existe desde 2005 , sendo normatizado através de uma Norma Operacional Básica de $n^{\circ} 130$ pelo Conselho Nacional de Assistência Social (CNAS). Em 2008, tivemos um Projeto de Lei $n^{\circ} 3.077 / 2008$, que tratava da necessidade de instituir o SUAS como lei, mas foi em 06 de julho de 2011 que foi sancionada pela atual Presidente do Brasil, Sra. Dilma Rousseff, a lei de $n^{\circ} 12.435$ que dispõe sobre o Sistema Único de Assistência Social (SUAS), tornando-o lei em todo o território nacional.

Desta maneira, o sistema constitui-se como um instrumento que viabiliza a materialização da Lei Orgânica de Assistência Social (LOAS), reforçando o aspecto da descentralização, da participação e também do não-contributivo, criando meios de articular Estado e Sociedade Civil nas três esferas de governo ${ }^{1}$. Esse novo sistema reforça a primazia da responsabilidade do Estado sob a garantia de acesso aos direitos dos usuários, sendo ele o responsável por dispor de meios para sanar suas necessidades básicas. Para a sua gestão, o SUAS possui eixos estruturantes, como bases organizacionais (NOB/SUAS/2005) que definem, organizam e fortalecem a execução da política nos territórios. Eles contribuem para a padronização e a qualidade dos serviços prestados, a consulta aos indicadores que ajudam na avaliação e nos resultados, assim como na nomenclatura dos serviços socioassistenciais.

\section{Os eixos estruturantes do Sistema Único de Assistência Social (SUAS)}

A descentralização político-administrativa na prestação de serviços por parte do estado começou a ser pactuada já na Carta Magna. Para a Política de Assistência Social, atuar de forma descentralizada possibilita atingir com maior eficiência os territórios e suas necessidades particularizadas. Para isso, divide a adesão dos municípios ao SUAS em três níveis de gestão: a inicial, a básica e a plena. A gestão inicial significa que o município começou a organizar a Assistência Social, sendo que seus serviços são ainda bastante restritos. Desta forma, os municípios que estão na gestão inicial têm a responsabilidade de:

[...] municiar e manter atualizadas as bases de dados dos subsistemas e aplicativos da Rede SUAS, componentes do Sistema Nacional de Informação; inserir no Cadastro Único as

\footnotetext{
${ }^{1}$ Três esferas de governo: União, Estados e Municípios.
} 
famílias em situação de maior vulnerabilidade social e risco, conforme critérios do Programa Bolsa Família [...] preencher o plano de ação no sistema SUAS-WEB e apresentar o relatório de gestão como forma de prestação de contas (NOB/SUAS, 2005, p.50).

A partir do momento que o município executa essas ações poderá requerer a gestão básica, para a qual tanto haverá um acréscimo de atividades com as quais poderá atender melhor sua demanda, quanto pode haver co-financiamento, pois ela é um nível em que o município deve trabalhar para

[...] prevenir situações de risco por meio do desenvolvimento de potencialidades e aquisições. Por isso deve responsabilizar-se pela oferta de programas ${ }^{2}$, projetos ${ }^{3}$ e serviços${ }^{4}$ socioassistenciais que fortaleçam vínculos familiares e comunitários que promovam os Benefícios de Prestação Continuada (BPC) e transferência de renda e que vigiem direitos violados no território (NOB/SUAS, 2005, p. 51).

Na medida em que o município vai assumindo novas atividades vai crescendo seu nível de gestão, suas responsabilidades, seus recursos e também sua abrangência de atendimento aos seus usuários. E, assim, o último nível é a gestão plena que é o "Âmbito em que o município tem a gestão total das ações de Assistência Social, sejam elas financiadas pelo Fundo Nacional de Assistência Social, mediante repasse fundo a fundo, ou que cheguem diretamente aos usuários [...]" (NOB/SUAS, 2005, p. 55). Este nível dá ao gestor a responsabilidade de assumir, no

\footnotetext{
${ }^{2}$ Os Programas "compreendem atividades integradas e complementares [...] com objetivos, tempo e área de abrangência definidos para qualificar, incentivar, potencializar e melhorar os benefícios e serviços socioassistenciais" (SETP, 2007, p. 6) que são ofertados à população.

\begin{abstract}
${ }^{3}$ Caracterizam-se como investimentos econômico-sociais nos grupos populacionais em situação de pobreza, buscando subsidiar técnica e financeiramente iniciativas que Ihes garantam meios e capacidades produtivas e de gestão para a melhoria das condições gerais de subsistência, elevação do padrão de qualidade de vida, preservação do meio ambiente e organização social, articuladamente com as demais políticas públicas (SETP, 2007 p. 06-7).
\end{abstract}

${ }^{4}$ Caracterizam-se pela prestação de atividades continuadas [...]
que visem a melhoria de vida da população e cujas ações estejam
voltadas para as suas necessidades básicas (SETP, 2007, p. 6). município, além das ações dos outros níveis de gestão, também a organização da Proteção Social Especial de Média e Alta Complexidade. Vale ressaltar que não é todo município que pode aderir ao nível da gestão Básica ou da Gestão Plena, pois a adesão aos níveis acima descritos é feita conforme o porte do município ${ }^{5}$. As ações e diretrizes previstas na legislação para a implementação da Assistência Social requerem critérios básicos para o seu desenvolvimento. Para isso é preciso que ocorra a descentralização político-administrativo entre as três esferas de governo. Descentralizar é diferente de municipalizar. Quando se descentraliza, se compartilham atribuições, recursos e etc; quando se municipaliza, há um repasse de responsabilidade para o município, sem, no entanto, compartilhar o poder, principalmente de decisão. A implementação do SUAS é um desafio, porém, um dos maiores é a descentralização, pois ela deve ocorrer no âmbito da União, dos Estados, do Distrito Federal e dos Municípios. São eles que devem trabalhar na formulação e implantação de ações com relação ao usuário, prestigiando os serviços municipais, porque respectivamente há uma proximidade maior dos assistidos, priorizando o vínculo familiar e comunitário.

Uma forma de colocar em prática o princípio da descentralização é implantar nos territórios de maior vulnerabilidade os Centros de Referência da Assistência Social (CRAS) ${ }^{6}$ e dos Centros Especializados de Referência da Assistência Social (CREAS) ${ }^{7}$, pois eles permitem o atendimento territorializado, intersetorial e o trabalho em rede. No entanto, é fundamental atentar-se para que em nome da descentralização não apenas se jogue as famílias que vivem em situação de pobreza para fora do espaço das cidades, sem acesso ao espaço público, e as oportunidades de ampliação de seus conhecimentos. É necessário que o território vulnerável receba infraestrutura para satisfazer as necessidades dos cidadãos atendidos, caso contrário, ele pode ser unicamente uma forma de esconder os pobres das

\footnotetext{
${ }^{5}$ Conferir a Norma Operacional Básica do Sistema Único de Assistência Social (NOB-SUAS).

${ }^{6}$ Este equipamento é responsável pela Proteção Social Básica.

${ }^{7}$ Este equipamento é responsável pela Proteção Social Especial, de média e alta complexidade.
} 
vistas da população que os repele nos espaços das cidades.

Considerando as ressalvas acima, o CRAS e o CREAS têm grande importância para o SUAS, pois é a forma concreta de descentralizar os serviços, a fim de chegar mais próximo possível de seus usuários. Estando no território das famílias, os profissionais conhecem melhor suas necessidades e o acesso aos seus direitos fica facilitado, mas é necessário que se leve o desenvolvimento para o território. Sob esse prisma, a territorialização é o "[...] reconhecimento da presença de múltiplos fatores sociais e econômicos que levam o indivíduo e a família a uma situação de vulnerabilidade ou risco social. É nos territórios que é operado o princípio da prevenção na Política de Assistência Social" (SUAS/PR, 2006, p. 18). Nesta política, o trabalho preventivo se constitui em significante desafio, pois historicamente, apenas se trabalhou de forma emergencial, com ações focalistas. É através do equipamento do CRAS que se pode trabalhar com as famílias visando o seu empoderamento ${ }^{8}$. Em suma, dentre todas as ações desenvolvidas pelo equipamento é imprescindível dar destaque para aquelas que irão proporcionar para o indivíduo ou para a família a promoção de sua autonomia, do protagonismo pela sua vida e pelo seu crescimento. A função do CRAS é dar suporte para isso, considerando que o sujeito que vive em situação de pobreza está inserido numa dinâmica de exclusão social decorrente do processo de acumulação capitalista e relações de exploração do trabalho. A centralidade do trabalho realizado através do CRAS está no atendimento à família, uma vez que seus membros precisam encontrar proteção e sustentabilidade, sendo ela sua referência, sua base, pois se a família está vulnerabilizada, ela não possui condições de proteger seus membros. O CRAS, portanto, é a referência da família, onde,

\footnotetext{
${ }^{8}$ A definição de empoderamento é próxima da noção de autonomia, pois se refere à capacidade de os indivíduos e grupos poderem decidir sobre as questões que lhes dizem respeito, escolher, enfim entre cursos de ação alternativos em múltiplas esferas política, econômica, cultural, psicológica, entre outras [...] resultante de processos políticos no âmbito dos indivíduos e grupos. Numa perspectiva emancipatória, empoderar é o processo pelo qual indivíduos, organizações e comunidades angariam recursos que lhes permitam ter voz, visibilidade, influência e capacidade de ação e decisão [...] equivale aos sujeitos terem poder de agenda nos temas que afetam suas vidas (HOROCHOVSKI e MEIRELLES, 2007, p.486).
}

através dele, é possível ter acesso aos demais direitos nas políticas setoriais, por ser ele a porta para os demais direitos. Para o desenvolvimento dessas atividades no CRAS é preciso que ele possua uma equipe ${ }^{9}$ de referência que trabalhe de forma interdisciplinar.

Como toda ação, a Política de Assistência Social requer investimentos para que possa efetivar-se e para compreendermos como se dá o seu financiamento faz-se necessário entender esse processo, no que se refere ao orçamento da gestão pública, que é "[...] um instrumento de planejamento da ação governamental composto das despesas fixadas pelo Poder Legislativo e que autoriza o Poder Executivo a realizá-las durante o exercício financeiro, mediante a arrecadação de receitas suficientes e previamente estimadas (ASSUMPÇÃO, 2007, p. 43). A Constituição Federal de 1988 coloca para administração pública alguns instrumentos que contribuem para a gestão: o Plano Diretor, o Plano Plurianual (PPA), a Lei de Diretrizes Orçamentárias (LDO) e a Lei Orçamentária Anual (LOA).

Segundo Bernardoni (2010), o Plano Diretor é o início de planejamento municipal que deve ser realizado por todos os municípios com mais de 20 mil habitantes, o qual deve estar em harmonia com a Lei Orgânica do Município e com a Lei de Responsabilidade Fiscal. Suas atualizações devem ser feitas pelo menos a cada dez anos. Os demais instrumentos devem ser norteados pelas diretrizes contidas no Plano Diretor. É importante lembrar que o Plano Diretor "Constitui-se no principal instrumento de planejamento sustentável desses municípios, contribuindo na formação de diretrizes para expansão urbana e desenvolvimento nas mais diversas áreas, visando sempre ao interesse da coletividade" (BERNARDONI, 2010, p. 51).

O PPA é um plano que é feito para ser cumprido em médio prazo, onde sua validade é de quatro anos. Segundo Assumpção (2007, p. 55), é um plano "[...] que visa atender às grandes metas do governo, refletindo, em linhas gerais, as propostas de campanha do agente político". Ele tem a vigência entre o início do segundo ano de mandato de um governo e finaliza no

\footnotetext{
${ }^{9}$ Essa equipe de referência deve ser composta por meio de concurso público, conforme prevê a Política de Recursos Humanos (NOB-SUAS/RH).
} 
primeiro ano de mandato do seu sucessor, onde "[...] o próprio chefe do Executivo herda o último ano de vigência do PPA do mandato anterior" (BERNARDONI, 2010, p. 53).

A LDO é um planejamento feito em curto prazo, busca o equilíbrio entre as receitas e as despesas de cada ano. É um elo entre o PPA e a LOA. Quando o gestor municipal vai elaborá-la, deve considerar todas as metas colocadas no PPA. Assim, a Lei de Responsabilidade Fiscal ${ }^{10}$ veio para regular a LDO, colocando para ela algumas atribuições, como:

[...] estabelecimento de critérios para limitação de empenho, no caso de frustração da arrecadação que possa levar ao desequilíbrio nas contas públicas; estabelecimento de critérios para a implantação da contabilidade de custos na Administração Pública; determinação de condições para a realização de transferências de recursos a entidades públicas e privadas; estipulação de metas e riscos fiscais com o objetivo de prevenir situações que possam levar ao desequilíbrio das contas públicas; instauração obrigatória de equilíbrio entre as receitas arrecadadas e as despesas legalmente empenhadas (BRASIL apud ASSUMPÇÃO, 2007, p. 56).

A LOA também é um planejamento pensado para ser cumprido em curto prazo. Ela deve ter por base a LDO. Segundo Assumpção (2007), o PPAe a LDO são documentos de planejamento, enquanto que a LOAé a indicação do como esse planejamento irá ser executado. Para a elaboração da LOA o administrador precisa pensar em várias questões da realidade, sendo que uma delas é a sua capacidade de arrecadação e "[...] expressa essa estimativa em números na LOA. Já as receitas são fixadas, isto é, a LOA expressa, em termos numéricos, o valor máximo da despesa para cada item do orçamento. Portanto, enquanto a RECEITA é PREVISTA, a DESPESA é FIXADA" (ASSUMPÇÃO, 2007, p. 58). Portanto, esses três instrumentos, PPA, LDO e LOA devem conter em si completa integração de ações e de previsão orçamentária. Um depende do outro para se consolidar, pois, "[...] fixam-se os valores necessários para a concretização dos projetos de governo que vão atender às necessidades da

\footnotetext{
${ }^{10}$ Lei Complementar n 101 de 04 de maio de 2000.
}

população, bem como indica-se a fonte de onde os recursos necessários sairão para fazer frente às despesas" (ASSUMPÇÃO, 2007, p. 60). A LOA, segundo Bernardoni (2010), é constituída de orçamentos, sendo: fiscal ${ }^{11}$, seguridade social $^{12}$ e investimentos ${ }^{13}$. Quando Bernadoni (2010) fala em administração direta e indireta significa que a direta é constituída nos municípios, pelas prefeituras, Câmara Municipal, secretarias e Procuradoria-Geral do Município. A administração indireta refere-se às entidades como autarquias, fundações, empresas públicas e sociedade de economia mista. Assumpção (2007) aponta um ciclo orçamentário: elaboração da proposta orçamentária, aprovação, veto ou sanção e publicação e execução de controle do orçamento. Quanto à fase da elaboração do PPA, LDO e LOA, é de responsabilidade do Poder Executivo elaborar a proposta e encaminhar ao Poder Legislativo para serem discutidos e posteriormente aprovados. Este pode aprovar diretamente, ou pode propor algumas alterações em forma de emendas. Depois disso retorna ao Executivo para que faça as alterações sugeridas através de vetos e/ ou sanções. Feito isso, tem a responsabilidade também de promulgar e publicar os documentos que irão nortear a gestão. Por fim, a última fase é a execução e controle, ou seja, momento de se pôr em prática tudo o que foi previsto. "Esse controle deve ser exercido pelo sistema de controle interno da entidade, pelo Poder Legislativo, como o auxílio dos Tribunais de Contas, bem como pelo controle social" (ASSUMPÇÃO, 2007, p. 61). Vale ressaltar que o processo de discussão e aprovação desses documentos deve ser participativo, ou seja, tanto os conselheiros quanto a população é chamada a participar. Assim, o PPA, a LDO e a LOA são instrumentos do planejamento público que dão sustentação e diretriz a toda a

\footnotetext{
11 "[...] o orçamento fiscal constitui-se no principal dos três orçamentos e refere-se aos Poderes, com seus fundos, órgãos e entidades da administração direta e indireta, inclusive fundações instituídas e mantidas pelo Poder Público".
} 
ação do governo. Neles devem estar previstos todos os programas, projetos e ações a serem desenvolvidas, assim como o recurso a ser utilizado pelo gestor. Cada Plano ${ }^{14}$, Programa ${ }^{15}$ ou Ação ${ }^{16}$ deve conter a justificativa, os objetivos, o público alvo, a forma de execução e o valor a ser gasto. De acordo com Bernardoni (2010, p. 39) da parte de quem planeja "[...] o processo de planejamento pressupõe uma visão holística de todo o cenário que envolve as políticas públicas, como também uma capacidade de gestão para integrar toda a estrutura da administração (organização, pessoas, equipamentos e recursos financeiros) $[\ldots]$ ".

É assim que os municípios planejam os orçamentos para as políticas públicas que eles administram, como no caso da Política de Assistência Social. O financiamento da Seguridade Social ${ }^{17}$, garantido constitucionalmente desde 1988 é a base do financiamento dessa política, sendo este um dos seus tripés. As instâncias de representação desse financiamento são os Fundos de Assistência Social (FAS) que estão organizados nas três esferas de governo. Qualquer recurso que precise chegar até o município, última instância, deve, necessariamente, ser repassado via fundo. Isso garante que os Conselhos, também nas três esferas, tenham controle sobre os gastos, uma vez que, estando no fundo facilita a prestação de contas para a comunidade. Nesse

\footnotetext{
14 "Consiste na definição das diretrizes gerais do governo [...] orientado por uma visão estratégica capaz de conferir foco às principais demandas [...]" (p.34-37).

15 "[...] decorrem sempre de um plano mestre. Consistem em um conjunto de ações denominadas de projetos, atividades, operações especiais e ações não orçamentárias, como objetivos preestabelecidos, visando a solução de um problema da sociedade e/ou ao aproveitamento de uma oportunidade de investimento [...]"(p.34-37).

${ }^{16}$ Compreendem os projetos, as atividades, as operações especiais e as ações não orçamentárias de um determinado programa [...]" (p.34-37).

17 "[...] participação de toda a sociedade; De forma direta e indireta; Nos orçamentos da União, dos Estados, do Distrito Federal e dos Municípios; Mediante contribuições sociais: Do empregador, da empresa e da entidade a ela equiparada na forma da lei incidentes sobre: a folha de salários e demais rendimentos do trabaIho pagos ou creditados, a qualquer título, à pessoa física que the preste serviço, mesmo sem vínculo empregatício; a receita ou o faturamento; o lucro. Do trabalhador e dos demais segurados da previdência social; Sobre a receita de concursos de prognósticos; Do importador de bens ou serviços do exterior ou de quem a lei a ele equiparar" (PNAS, 2004, p. 48).
}

sentido, "[...] o financiamento dos benefícios se dá de forma direta aos seus destinatários, e o financiamento da rede socioassistencial se dá mediante aporte próprio e repasse de recursos fundo a fundo [...]" (PNAS, 2004, p. 49).Destarte, nenhum recurso da Assistência Social pode ser gasto sem a aprovação das instâncias de deliberações que são os Conselhos. Da mesma forma, a prestação de contas de determinado recurso também depende da aprovação dos mesmos. Isso se chama controle social dos gastos públicos. Para que possa haver o repasse via fundo é necessário que o município tenha em pleno funcionamento o Conselho de Assistência Social, o Fundo Municipal de Assistência Social e que tenha elaborado o Plano de Assistência Social. Além disso, é preciso que se comprove os recursos que o município destina para a Assistência Social"[...] alocados em seus respectivos Fundos de Assistência Social; o cumprimento, pelo município, das obrigações assumidas; que haja regularidade na aplicação dos recursos e que as contas do exercício anterior sejam aprovadas pelo respectivo Conselho" (TCU, 2009, p. 26).Para que o município tenha tudo isso em funcionamento precisa estar constantemente planejando suas ações e para tal atividade pode contar com instrumentos de gestão ${ }^{18}$ que facilitam esse processo. Segundo o TCU (2009), o Plano de Assistência Social é um instrumento de planejamento estratégico que organiza e norteia as ações para a execução da política. Quem elabora o Plano é o órgão gestor e depois passa pelo Conselho para que este possa discutir, pedir reformulações e aprovar. Assim, todo o recurso previsto deve ser aplicado de acordo com as prioridades que foram elencadas no plano de Assistência Social. Esse processo também o Conselho acompanha, fiscaliza e aprova ou não. Quando há irregularidades o Conselho pode questionar e pedir que seja retificado. Caso não seja, ele pode não aprovar a aplicação dos recursos do município.

Para o seu desenvolvimento, a política pública conta com os seus trabalhadores, os quais são orientados por uma Política de Recursos

\footnotetext{
${ }^{18}$ Os instrumentos de gestão são o Plano de Assistência Social, o Relatório Anual de Gestão, o Orçamento, o Monitoramento, a Gestão da Informação e a Avaliação. Eles constituem-se ferramentas imprescindíveis para uma gestão democrática e competente da política.
} 
Humanos $^{19}$. Ela foi elaborada para que pudesse enfrentar a precarização do trabalho, haja vista que isso influência diretamente na prestação de serviços continuados e com qualidade, que é sua obrigação. A precariedade do trabalho não aparece apenas nas empresas privadas, mas também no Estado através de contratos temporários, testes seletivos, licitações e outras formas que são instáveis e com baixa remuneração. Não raras vezes, sempre que ocorre a troca de gestor (prefeito) nas prefeituras, muda-se, quase que completamente, o quadro de funcionários, uma vez que cada gestão tem seus cabos eleitorais para empregar. Na PNAS (2004) já havia uma preocupação com essa situação, e até pontuava algumas questões que mais tarde foram incorporadas à Norma Operacional Básica de Recursos Humanos do SUAS (NOB/RH-SUAS, 2006), mas não se tratava ainda de uma política. Com a aprovação da NOB/RH-SUAS, desponta um começo de mudança porque, no contexto da Política de Assistência Social, estão previstas mudanças fundamentais que contribuem com o enfrentamento da precarização do trabalho, pois "[...] o SUAS vem se consolidando, e a gestão do trabalho na Assistência Social carece de uma atenção maior devido a sua importância para a consolidação do sistema" (NOB/RH-SUAS, 2006, p. 17). Então, a implementação do SUAS, além de outros fatores, também depende dos trabaIhadores que vão operá-lo. E para a Secretaria Nacional de Assistência Social, esse documento é uma das primeiras iniciativas para a consolidação de uma política na área da gestão do trabalho. Seus princípios dizem respeito à gestão do trabalho no âmbito das políticas públicas, as quais são incorporadas pela Assistência Social e também pela Política de Recursos Humanos a fim de tornar as relações de trabalho mais dignas e também estáveis entre os trabalhadores e os usuários dos serviços. Desta maneira, a gestão do trabalho no SUAS garante que os trabalhadores da área tenham Planos de Carreira, Cargos e Salários (PCCS). Isso significa um incentivo à formação continuada e também que os salários sejam definidos por nível de formação, possibilitando, por exemplo, que todos que tenham nível

\footnotetext{
${ }^{19}$ Conferir a Norma Operacional Básica de Recursos Humanos do Sistema Único de Assistência Social (NOB-SUAS/RH).
}

superior recebam o mesmo valor, não fazendo acepção de profissão. Isso é fundamental para a Política de Assistência Social, pois "As possibilidades de atuação profissional não podem ser desvinculadas das condições e processos em que se realiza o trabalho" (CFESS, 2007, 43).

Outro aspecto importante que a NOB/ RH-SUAS ressalta é a forma de se contratar 0 trabalhador(a) para seu serviço. A partir dela, esse contrato só é possível por meio de concurso público, dado que este possibilita relações estáveis com os usuários. No que tange a gestão do trabalho no SUAS e para que haja a prestação de serviços com qualidade é necessário "O estabelecimento de relações de trabalho estáveis, a garantia institucional e condições e meios necessários à realização das atividades são indispensáveis para o exercício profissional" (CFESS, 2007, 43 - 44).Para o CFESS (2007), a gestão do trabalho no SUAS, além de garantir maior qualidade na prestação de serviços, também colabora no enfrentamento das relações de trabalho precárias impostas pelo sistema capitalista de produção, onde o que impera é o lucro. Além do mais, é também uma forma de garantir os direitos trabalhistas dos profissionais que têm como função também a garantia de direitos sociais.A realização dessas estratégias requer comprometimento do gestor em assegurar ao usuário o acesso aos programas, projetos, bens e serviços que lhe são de direito.

A informação e o monitoramento são fundamentais para a avaliação das ações das políticas públicas. São processos que precisam ser desenvolvidos antes, durante e depois da execução de qualquer serviço, o que Carvalho (2001) chama de avaliação ex-ante e postfacto. A avaliação ex-ante nos mostra que é necessário que se verifique "[...] as alternativas possíveis e os impactos projetados sobre cada uma das alternativas quanto a custos, nível de adesão da organização e dos beneficiários, padrões de intervenção, estratégias, processos e resultados (CARVALHO, 2001, p. 63). Tratase de uma avaliação chamada de diagnóstico e de proposta. Feito isso é fundamental que haja um acompanhamento das ações propostas, o que é chamado pela autora de monitoramento. Nesse processo é possível, além de acompanhar a execução das atividades, rever o planejamento, as estratégias e as necessidades 
que surgem durante o processo, ou seja, "[...] objetivando corrigir distorções durante o próprio desenvolvimento do projeto [...]" (CARVALHO, 2001, p. 64). E também para completar o ciclo avaliativo a autora propõe uma avaliação postfacto, isto é, depois do fato, pois "[...] os projetos podem ter resultados e impactos esperados e não esperados, tangíveis e intangíveis, imediatos ou de médio prazo. Por isso, a avaliação de resultados e impactos deve ocorrer não só ao término dos projetos, mas também depois de algum tempo" (CARVALHO, 2001, p. 64). As políticas públicas não podem escapar desse processo, uma vez que primam pela qualidade dos serviços prestados, não apenas momentaneamente, mas também através dos resultados alcançados em longo prazo. Para isso a política possui um sistema de informação, monitoramento e avaliação que visa garantir o acompanhamento de todo o processo da prestação dos serviços socioassistenciais e que permitem mensurar a eficiência e a eficácia "[...]das ações previstas nos Planos de Assistência Social; a transparência; o acompanhamento; a avaliação do sistema e a realização de estudos, pesquisas e diagnósticos a fim de contribuir para a formulação da política pelas três esferas de governo" (PNAS, 2004, p. 55).Com isso o sistema favorece a participação e o controle social das ações dentro da política, pois qualquer pessoa pode acompanhar o andamento e o controle das ações através dos dados que nele são inseridos. E não só a população, mas, também, os próprios gestores, pois para perceber o desenvolvimento do serviço com qualidade é necessário que se monitore e avalie constantemente. Ela possui uma rede de sistema informações que são interligados e são constantemente aprimorados para que a tecnologia possa contribuir com o monitoramento, com vistas à melhoria da prestação de serviços. E para alimentar esse sistema existem os chamados Instrumentos de Gestão que têm o objetivo de "[...] propiciar o planejamento, execução, monitoramento e avaliação dos serviços, programas e projetos, e benefícios socioassistenciais além de municiar as instâncias do sistema descentralizado e participativo de assistência social" (CADERNO SUAS II, 2007, p. 27).

A matricialidade sócio familiar é outro eixo do SUAS. Pois bem, desde os primórdios da década de 1970 "[...] a família vem sendo re- descoberta como um importante agente privado de proteção social" (PEREIRA, 2009, p. 26) e por isso a família tem sido foco de atenção em todas as políticas públicas, já que não há uma política específica no Brasil e nem fora dele, e ela tornou-se, também, objeto de discussão no meio científico, devido à relação que tem com o Estado, que é o responsável pela promoção de políticas de enfrentamento de suas demandas. Pereira (2009), foca suas discussões, a partir dos anos 70 e 80, especialmente na década de 90 , quando as receitas neoliberais acirram as desigualdades sociais e, ao mesmo tempo, há a discussão sobre a necessidade de um Estado mais forte, presente e interventor; diante disso os neoliberais buscam um Estado afastado das demandas sociais deixando-as por conta da sociedade. Destarte, Estado e Sociedade Civil, supostamente formam parcerias para enfrentar as expressões da Questão Social que atingem diretamente a família, cada qual utilizando de seus estratagemas: "[...] o Estado, com o recurso do poder e, portanto, da autoridade coativa, que só ele possui; o mercado, com o recurso do capital; e a sociedade, da qual a família faz parte, com o recurso da solidariedade" (PEREIRA, 2009, p. 32). Estas instituições formam, segundo a autora, uma rede que deveria prover o bem-estar. E por ser "[...] considerada a célula mater da sociedade ou a base sobre a qual outras atividades de bem-estar se apoiam, a família ganhou relevância atual justamente pelo caráter informal, livre de constrangimentos burocráticos e de controles externos (PEREIRA, 2009, p. 36). No entanto, Estado e mercado sutilmente afastam-se, deixando a responsabilidade de proteção apenas para a família. Isso é perigoso, pois focando na família pode se desviar do verdadeiro responsável pelas desigualdades sociais. Mesmo que o SUAS tenha a família como centralidade de suas ações ${ }^{20}$ é fundamental que os profissionais instituam um trabalho comunitário, fortaleçam as organizações de bairro, de Movimentos Sociais e empreendam junto a seus usuários o fortalecimento da autonomia, a ampliação dos horizontes críticos, para que estes possam perceber que estão inseridos

\footnotetext{
${ }^{20}$ É importante frisar que essa é uma tendência das políticas sociais a partir de década de 90 , quando da introdução do ideário neoliberal na gestão pública.
} 
numa dinâmica maior, a de um sistema capitalista excludente, e que sua situação de pobreza não está relacionado à falta de capacitação ou capacidade, mas porque existe um processo de exclusão como parte inerente ao sistema. Assim, a família, por si só, não é uma instituição considerada capaz de prover todas as necessidades de seus membros, embora haja certa tendência de afirmação disso por parte do Estado e do mercado. Ela é envolta em duas modalidades de situações cotidianamente reveladas pela autora como forte e fraca, ou seja, apesar da importância que a família tem para os seus, possui também suas fragilidades decorrentes da sociedade que a fragiliza. Nesse sentido, a autora explica que a família pode ser:

Forte, porque ela é de fato um lócus privilegiado de solidariedades, no qual os indivíduos podem encontrar refúgio contra o desamparo e a insegurança da existência. Forte, ainda, porque é nela que se dá, de regra, a reprodução humana, a socialização das crianças e a transmissão de ensinamentos que perduram pela vida inteira das pessoas. Mas ela também é frágil, 'pelo fato de não estar livre de despotismos, violências, confinamentos, desencontros e rupturas' [...] (PEREIRA, 2009, p. 36-37).

Como a família se modificou criando uma série de arranjos e não sendo mais apenas como nuclear, o maior desafio dos que pensam as políticas públicas está em considerar esses novos modelos de família que emergem na atualidade. Sarti (2008) discute a família na atualidade numa perspectiva de rede, ou seja, quando se pensa em trabalhar com família é necessário localizar suas redes de contatos na comunidade, pois "[...] as dificuldades enfrentadas para a realização dos papeis familiares no núcleo conjugal, diante de uniões instáveis e empregos incertos, desencadeiam arranjos que envolvem a rede de parentesco como um todo, a fim de viabilizar a existência da família" (SARTI, 2008, p. 29). Para a autora, em especial nas famílias que vivem em situação de pobreza, os membros fragilizados estão sob responsabilidade da rede de sociabilidade criada pelos parentes e não parentes. É o que ela chama de rede, e, por isso, é importante que as políticas públicas tenham claro que "[...] trabalhar com família requer a abertura para uma escuta, a fim de localizar os pontos de vulnerabilidade, mas também os recursos disponíveis [...] cada família constrói sua própria história, ou o seu próprio mito, entendido como uma formulação discursiva em que se expressam o significado e a explicação da realidade vivida [...]" (SARTI, 2008, p. 26-27).Se para toda a sociedade a família ainda é tida como um valor, segundo a autora, entre a população pobre isso tem maior relevância, pois é o único bem que se tem. No entanto, ela é extensa, ou seja, não se restringe apenas às pessoas do mesmo sangue, mas àquelas com quem se pode contar. Como foi dito acima, é comum entre as mais diversas políticas públicas pensar na centralidade da família no âmbito de suas ações. O SUAS não deixou de considerar esse aspecto. Tanto é verdade que o seu primeiro eixo estruturante trata da família, por também considerar fundamental essa discussão.

A matricialidade sociofamiliar, dessa forma, constitui-se como um dos pilares do SUAS, porque no desenvolvimento dos serviços socioassistenciais é fundamental considerar todas as pessoas que vivem sob um mesmo teto e suas demandas. Isso porque as transformações econômicas e sociais determinam a composição familiar ressignificando seus papéis. As contradições existentes na sociedade brasileira fragilizam a família, assim como a sua função protetora originária de seus membros. No entendimento da Política de Assistência Social a família é o "[...] espaço privilegiado e insubstituível de proteção e socialização primárias, provedora de cuidados aos seus membros, mas que precisa também ser cuidada e protegida" (PNAS, 2004, p. 42).

Destarte, entende-se que as mudanças ocorridas no mundo do trabalho, tais como: a exploração, a precarização, o subemprego, o desemprego, assim como o acirramento das expressões da Questão Social atingem diretamente a família e seus membros. Por isso, ao se olhar a família na atualidade é preciso, antes de tudo, compreender que ela:

[...] é mediadora das relações entre sujeitos e a coletividade, delimitando, continuadamente os deslocamentos entre o público e o privado, bem como geradora de modalidades comunitárias de vida [...] um espaço contraditório, cuja dinâmica cotidiana é marcada por conflitos e geralmente, também, por desigualdades, além de que nas sociedades capitalistas 
a família é fundamental no âmbito da proteção social (PNAS, 2004, p. 41).

Compreendem-se, assim, as novas configurações de família, percebendo as mudanças com relação ao antigo modelo, em que os membros eram formados por pai, mãe e filhos, pois com a modernização da sociedade ela também passou por transformações. Para as políticas públicas tem-se um novo conceito de família que amplia a cobertura dos serviços quando entende que família é "[...] um conjunto de pessoas que se acham unidas por laços consanguíneos, afetivos e/ou de solidariedade" (PNAS, 2004, p. 41). Assim, abre-se espaço para acolher as famílias formadas por pai e filhos, mãe e filhos, avô/avó e netos, pessoas que moram em repúblicas, casais de homossexuais etc..., enfim, todos os grupos que vivem sob o mesmo teto são considerados família e devem ter garantido o acesso aos seus direitos. "Dentre essas mudanças pode-se observar um enxugamento dos grupos familiares (famílias menores), uma variedade de arranjos familiares (monoparentais, reconstruídas), além dos processos de empobrecimento acelerado e da desterritorialização das famílias geradas pelos movimentos migratórios" (PNAS, 2004, p. 42). Para a PNAS/2004, centrar o trabalho na família é um passo para a superação das ações emergenciais e focalistas. Então, para que ela possa "[...] prevenir, proteger, promover e incluir seus membros é necessário, em primeiro lugar, garantir condições de sustentabilidade para tal" (PNAS, 2004, p. 41). Essa tarefa é obrigação do Estado Democrático de Direito que tem a função de cuidar de seus cidadãos no sentido de garantir-lhes condições básicas de sobrevivência.

A concepção de participação remete-se ao conceito de democracia participativa que entra em voga no Brasil a partir da década de 70 , quando se começa a pensar numa reforma democrática, tema enfatizado pelos Movimentos Sociais em todo o país que querem uma nova forma de fazer política, de acordo com Moura (2009) e Siqueira (2006). "No debate quanto à reforma da democracia, a ideia de participação de grupos e camadas da população tidas como pouco representadas, constituiria incentivo para estimular o melhor funcionamento das instituições políticas" (MOURA, 2009, p. 47). Os Movimentos Sociais são os atores coletivos que buscam trans- formação da realidade brasileira e acreditam que só é possível quando eles exercem pressão sobre o Estado e o capital. "A busca pelo reconhecimento do direito de se ter direitos foi o imperativo desses movimentos. Busca-se ainda o direito de participar e de decidir sobre as ações estatais, influenciando as políticas e fiscalizando a operacionalização dos serviços sociais (SIQUEIRA, 2006, p. 48).

Souza (2009) explica que existem três concepções consideradas por ela como básicas no que diz respeito à participação, são elas: a participação comunitária, a participação popular e a participação social. Segundo ela, a participação comunitária surgiu no século XX e tinha uma conotação conservadora por enfatizar a execução de atividades sem a preocupação com o pensar as ações e a eleição de prioridades. Já a participação popular surge a partir de 1970 quando a efervescência dos Movimentos Sociais, que tinham um caráter reivindicatório, apontava para a urgência de fiscalizar as ações estatais. E, por último, a participação social que nasce com o processo de democratização no país. Ela se preocupa com a gestão das políticas na busca da consolidação dos direitos sociais (SOUZA, 2009).

A consolidação dessa reivindicação dos Movimentos Sociais tem início com a institucionalização da participação popular na Constituição Federal de 1988 no parágrafo único do artigo primeiro, quando diz: "Todo poder emana do povo, que o exerce por meio de representantes eleitos diretamente [...]" (BRASIL, 1988, Art 10). E quando se trata da Assistência Social, que é a discussão deste trabalho, a CF/88 deixou ainda mais claro algumas diretrizes, como a "[...] II - participação da população, por meio de organizações representativas, na formulação das políticas e no controle das ações em todos os níveis [...]" (BRASIL, 1988, Art. 204).Já Moura (2009), embasada na concepção de Pateman (1992), também mostra que existem três formas de participação, que são:

[...] i) a pseudoparticipação (em que os indivíduos apenas são consultados sobre algum assunto e endossam as decisões do líder, ou seja, não ocorre, de fato, participação alguma na tomada de decisão); ii) a participação parcial (em que muitos tomam parte no processo decisório, mas o poder final de decidir pertence a apenas uma das 
partes); e iii) a participação plena (em que cada membro isoladamente tem igual poder de determinar o resultado final das decisões) (MOURA, 2009, p. 43).

A autora defende que a participação é elemento primordial para a construção da democracia, pois ela "[...] capacitava as pessoas para avaliar melhor tanto a esfera pública como privada [...]" (MOURA, 2009, p. 43). Dessa maneira, para a participação popular podem existir vários modos e instâncias, objetivos e metas, circunstâncias e motivações. As formas e os espaços de participação variam conforme o contexto histórico e a cultura de cada sociedade e por isso a participação "[...] pode ser entendida como processo social, no qual o homem se descobre enquanto sujeito político, capaz de estabelecer uma relação direta com os desafios sociais [...]" (SOUZA, 2009, p. 170).De qualquer modo, para a autora, a participação social requer que os sujeitos individuais compreendam-se como sujeitos coletivos que têm necessidades comuns, e por isso sentem a necessidade de buscar isso conjuntamente. Avelar (2004) complementa essa ideia apontando que todo caso é uma ação de sujeitos com um objetivo comum, portanto "[...] é a ação que se desenvolve em solidariedade com outros no âmbito do Estado ou de uma classe, com o objetivo de modificar ou conservar a estrutura (e, portanto, valores) de um sistema de interesses dominantes" (AVELAR, 2004, p. 225). Aqueles que participam "[...] são partes que desejam ser parte ou tomar parte de algo" (NOGUEIRA, 2005, p. 129).

Avelar (2004) apresenta três canais de participação: o canal eleitoral, o canal corporativo e o canal organizacional. O primeiro compreende as atividades de partidos políticos; o segundo trata da representação de interesses particulares dentro do sistema estatal; e o último trata das organizações não institucionalizadas, e um dos exemplos que o autor apresenta são os movimentos sociais. Já Nogueira (2005) discute em seu texto quatro formas de participação, são elas: a participação assistencialista, a participação corporativa, a participação eleitoral e a participação política. A primeira está relacionada à filantropia ou à solidariedade. Antes da afirmação dos direitos sociais essa era a forma mais comum de participação. A segunda forma, a participação corporativa, de acordo com o autor, está relacionada às categorias de profissionais quando defendem determinados interesses, sendo esta característica específica da época do sindicalismo. "Trata-se de uma participação fechada em si, que se objetiva sobretudo com um propósito particular, em maior ou menor medida excludente: ganham apenas os que pertencem ao grupo ou à associação" (NOGUEIRA, 2005, p. 131). Ele afirma ainda que essa forma também é parecida com a participação assistencialista no quesito de serem práticas universalizadas. A terceira forma de participação apresentada pelo autor é a eleitoral, onde cresce a defesa por interesses mais coletivos, porque interfere no coletivo ao se tratar da questão da governabilidade do Estado. Ela está significativamente relacionada ao processo eleitoral, ao voto em si, e isso se mostra como uma limitação da mesma. Segundo Nogueira (2005), ao se prender apenas na questão eleitoral, o cidadão está individualizando as decisões. E, por fim, o autor mostra a quarta modalidade de participação, que é a política. Esta inclui tanto a participação eleitoral quanto a corporativa. Esse tipo de participação considera a comunidade como um todo, no sentido do coletivo, que procura defender também os interesses coletivos, e está relacionada também ao Estado e ao controle de suas ações. Nesse tipo de participação o protagonista é sempre o cidadão que se organiza em categorias de representação e busca garantir interesses coletivos. No entanto, é preciso deixar claro que isso não exclui a possibilidade de existir busca por interesses particularizados revestidos de coletivos que podem acontecer entre os sujeitos participantes. Nogueira (2005) mostra que a participação remete logo à questão do poder que perpassa a relação. "A rigor, ainda que nem toda a participação seja imediatamente política, não há participação que não se oriente por algum tipo de relação com o poder - tanto com o poder de outros atores quanto com o de determinados centros organizacionais e decisórios" (NOGUEIRA, 2005, p. 129). Isso é mais forte ainda quando se trata de participação em espaços públicos, como no caso dos Conselhos de política, dos quais fazem parte segmentos do Estado e da Sociedade Civil. Quando se trata de um governo que preza pela democracia e conta com a participação da população, entendendo 
que ele é apenas um representante que administra a coisa pública, existe maior probabilidade de haver efetividade do controle social sobre suas ações. Agora, quando o governo ainda vive resquício do conservadorismo os espaços de participação popular sofrem pressões e manipulações, impedindo que a população tenha o poder de participar.

Diante disso Tatagiba (2002) nos diz que o desafio maior está no compartilhamento do poder entre Estado e Sociedade Civil. Existem conflitos nesta relação, pois se trata de permitir que alguém (há pouco compreendida como foco do favor), passe a discutir prioridades e investimentos de recursos. Legalmente falando, os Conselhos têm o poder de deliberar sobre as ações estatais, porém, o Estado precisa saber partilhá-lo. "Os governos têm resistido - de forma mais ou menos acentuada dependendo da natureza do governo e do seu projeto - às novas formas de fiscalização, controle e participação da Sociedade Civil no processo de produção das políticas públicas" (TATAGIBA, 2002, p. 79).

Compreende-se, assim, que nem o Estado, nem a Sociedade Civil estão livres da busca pela efetivação do poder. Ambos são heterogêneos e podem buscar nos espaços de participação a legitimidade de interesses particulares, e, desta maneira "A centralização do poder nas mãos do executivo fragiliza, em muitos casos, a autonomia dos conselhos diante das condições que os governos reúnem para interferir, neutralizar ou mesmo minar as ações e decisões do colegiado" (SOUZA, 2009, p. 184). Para compreender como o conflito entre interesses privados pode ocorrer na prática cotidiana, podemos exemplificar da seguinte maneira: um representante de entidade pode estar participando de um Conselho preocupado apenas em cooptar recursos para a sua instituição, sendo que, na realidade, sua função ali é discutir coletivamente as prioridades de todos os segmentos por ele representados e deliberar prioritariamente. Da mesma maneira, o Estado pode eleger um representante que irá apenas legitimar suas ações, procurando evitar maiores conflitos ou até ocultar dados importantes que possam questionar as suas ações. Quando existe essa prática, acontece a neutralização daquele espaço que deve ter um enfoque de garantir prioridades para o coletivo.
A participação política está relacionada à participação cidadã, modalidade trazida pelo processo de democratização do país. Esse tipo de participação se preocupa com o compartiIhamento das decisões estatais entre Estado e Sociedade Civil, referindo-se às políticas públicas e seus espaços participativos e não está preocupada com a diminuição das forças antagônicas em movimento. "A participação que se dedica a compartilhar decisões governamentais, a garantir direitos, a interferir na elaboração orçamentária ou a favorecer sustentabilidade para certas diretrizes concentra-se muito mais na obtenção de vantagens e de resultados do que na modificação de correlações de forças ou de padrões estruturais" (NOGUEIRA, 2005, p. 142).Apesar desses impasses, é fundamental que a população continue participando desses espaços, pois "[...] a participação política é instrumento de legitimação e fortalecimento das instituições democráticas e de ampliação dos direitos de cidadania" (AVELAR, 2004, p. 223). É uma forma de impactar positivamente na gestão das políticas, uma vez que os cidadãos participantes exercem poder de mudança neste espaço, apesar de todas as contrariedades.

No tocante à Política de Assistência Social, todos os cidadãos podem participar do processo de gestão da mesma, inclusive as pessoas que se utilizam de seus serviços. Esse é um desafio inerente ao processo de democratização de todas as políticas, e mais ainda da Assistência Social, pois ela possui uma marca histórica relacionada a não participação, onde o sujeito era tratado como cliente. Assim, se a sociedade como um todo tem dificuldade de participar do controle das ações públicas, pode se imaginar o que isso significa quando se trata dos usuários da Assistência Social. Mas, não se trata de algo impossível, mas de aprendizado, pois são eles que utilizam os serviços e podem avaliá-los de forma efetiva. De acordo com Avelar (2004, p. 234) “[...] só se resulta em democratização quando a participação se materializa em políticas para a efetiva extensão de direitos e que a cada nova classe de direitos alcançados corresponda à efetiva integração de cada membro com igual calor na coletividade política". A participação popular pode gerar impacto na gestão das políticas sociais quando os sujeitos ocupam os espaços, como os Conselhos de direitos. Focaremos este estudo, a

314 Emancipação, Ponta Grossa, 14(2): 303-320, 2014. Disponível em <http://www.revistas2.uepg.br/index.php/emancipacao> 
partir daqui, nos Conselhos de Assistência Social para compreender as possibilidades e limites da participação popular.

$\mathrm{Na}$ medida em que a participação alarga-se e ativa-se, assumindo ou não uma forma gerencial, passa a condicionar os governos e a administração pública. A gestão é obrigada a se auto-reconfigurar, a se desenhar de outro modo, a formar novos recursos humanos bem como organizações diferentes. Ao tornar-se participativa, anuncia o aparecimento de um novo campo semântico no universo gerencial (NOGUEIRA, 2005, p. 145).

Os Conselhos são um dos canais de participação popular, de fiscalização e de exercício do controle social por excelência na Política de Assistência Social, sendo que em qualquer instância ele está "[...] Inserido na esfera pública; caracterizado como instituição [...] (governamental e não governamental); quebra do monopólio de velhos atores (executivo, legislativo, partidos, sindicatos); estabelece um processo de interlocução e negociação com atores diversos, em especial gestores, trabalhadores, prestadores e usuários" (CIPEC21, 2002, p. 26). Eles não governam, mas verificam e avaliam demandas e resultados, considerando as prioridades, com o intuito de dar respostas aos interesses coletivos e públicos. Tem características peculiares. Segundo o CIPEC (2002), os Conselhos são órgãos especiais, autônomos e independentes, deliberativos, colegiados, normativos e constituem-se como espaço público de negociação.

No entanto, como a Sociedade Civil ainda não aprendeu a participar e exercer o controle e a fiscalização nos espaços dos Conselhos pode acontecer que os governos utilizem esses espaços como legitimadores de uma prática nem sempre democrática. Nesse caso, eles perdem o caráter de deliberativos passando a ser meramente consultivos, compactuando muitas vezes com uma má gestão. Sempre que acontece algo assim, o próprio Conselho está fortalecendo o autoritarismo e enfraquecendo a democracia. Porém, alerta Tatagiba (2002, p. 91), se o Conselho não tem força de deliberar, pode fiscalizar e controlar as ações do Estado, pois "[...] conselhos com baixa capacidade deliberativa podem ser fortes no

\footnotetext{
${ }^{21}$ Centro Interdisciplinar de Pesquisa e Consultoria em Políticas Públicas (CIPEC).
}

controle da aplicação dos recursos orçamentários ou na execução dos programas e projetos", pois a efetividades das políticas dependem da efetiva aplicabilidade dos recursos a elas destinados.

A composição dos Conselhos se dá de forma paritária, sendo que $50 \%$ das cadeiras devem ser preenchidas por representantes usuários $^{22}$ dos serviços ou organização destes, dos trabalhadores da área ${ }^{23}$ e das entidades ${ }^{24}$, sendo estes eleitos em Conferências. E os outros 50\% preenchidos por representantes governamentais, que são indicados pelo governo, normalmente servidores públicos. Os representantes governamentais são indicados pelo chefe do executivo nas três esferas. Compreendemos essa questão da indicação como uma fragilidade da composição dos Conselhos, uma vez que os representantes não governamentais também deveriam ser eleitos em Conferências e não indicados pelo poder executivo. No processo de escolha e indicação do governo, este pode, tranquilamente, buscar um sujeito que vai defendê-lo, e não fiscalizá-lo. Isso não favorece a efetividade do controle social. As entidades são aquelas que prestam serviços de assistência social. Por isso, "[...] consideram-se entidades e organizações de assistência social aquelas que prestam, sem fins lucrativos, atendimento e assessoramento aos beneficiários abrangidos por esta lei, bem como os que atuam na defesa e garantia de direitos" (LOAS, 1993, Art. 3).

Em 2009 foi aprovada a Lei de $\mathrm{n}^{0} 12.101$ que dispõe sobre a certificação das entidades socioassistenciais; essa lei muda a forma de fiscalização dos Conselhos com relação a elas. Até esse momento todas as entidades que prestassem serviços de assistência social, mesmo sendo de outra política, como educação e saúde,

\footnotetext{
22 São representantes da sociedade, destinatários da assistência social ou organizados em entidades. Alguns exemplos são: Associação de Moradores, Clubes de Mães, Associações Comunitárias, Movimentos Sociais (CIPEC, 2002, p. 41)

${ }^{23}$ São representantes de organismos/entidades privadas, constituídas como pessoas jurídicas que lutam na defesa de interesses coletivos na área social. Alguns exemplos são: Sindicatos Conselhos representantes de categorias (Psicologia, Advocacia, Serviço Social, Saúde...) (CIPEC, 2002, p. 41).

${ }^{24}$ São representantes das entidades que atuam no setor de assistência social, prestando serviços e atendimento à população. Alguns exemplos são: Entidade de Atendimento a Família, às Crianças e Adolescentes, às Pessoas com deficiência, Idosos.. (CIPEC, 2002, p. 41).
} 
eram certificadas pelo Conselho de Assistência Social. A partir dessa Lei tudo muda, sendo que entidades que em seu estatuto preponderam questões de saúde, serão certificadas e fiscalizadas pelo Ministério da Saúde; aquelas em que preponderam questões educacionais serão fiscalizadas pelo Ministério da Educação; e, enfim, as entidades de Assistência Social serão encaminhadas diretamente ao Ministério do Desenvolvimento Social e Combate à Fome (MDS). Porém, as entidades das políticas de saúde e educação poderão registrar no Conselho de Assistência Social apenas os projetos que sejam, de fato, socioassistenciais, os quais serão acompanhados pelos referido Conselho.

A Resolução de $n^{\circ}$. 16, aprovada em 16 de maio de 2010, define os parâmetros nacionais para a inscrição de entidades e organizações de Assistência Social, bem como dos serviços, programas, projetos e benefícios socioassistenciais nos Conselhos de Assistência Social dos municípios e do Distrito Federal. Ela apresenta três tipos de entidades que podem ser organizadas pela Sociedade Civil para prestar serviços: entidade de atendimento, de assessoramento e de defesa de direitos. O ano de 2010 é, portanto, o ano de adaptação e capacitação dos conselheiros sobre essa nova lei, para que possam certificar e fiscalizar as entidades parcerias do governo na prestação de serviços à população. Os trabalhadores da área são representados normalmente pelos Conselhos de classe e os usuários são aqueles destinatários dos serviços da política e a sua participação tem significativa importância, pois são, por excelência, avaliadores destes serviços. Cada esfera de governo define, em seu regimento interno, a composição de seu Conselho. O Conselho é um órgão fundamental para a Política de Assistência Social, pois nada pode ser implementado nela sem a aprovação deste em qualquer esfera. Portanto, para o acompanhamento da Política de Assistência Social, têm-se várias instâncias de Conselhos, que são: o Conselho Nacional de Assistência Social (CNAS), o Conselho Estadual de Assistência Social (CEAS) e o Conselho Municipal de Assistência Social (CMAS). Esses órgãos são as instâncias deliberativas do Sistema Descentralizado e Participativo da política e visam o controle social e a fiscalização em cada esfera de governo. Diante disso, a PNAS precisa ser coordenada nacionalmente em conformidade com o CNAS, pois toda decisão a ser tomada deve, obrigatoriamente, passar pela discussão, aprovação e deliberação do CNAS. Os Estados e os Municípios também têm essas competências, só que suas responsabilidades restringem-se às suas respectivas esferas. O Conselho pode, em cada esfera, eleger comissões de forma paritária para dividir as tarefas. De forma geral, as comissões são divididas em três: Comissão Temática de Política Social Básica; Comissão Temática de Documentos e Cadastro; Comissão Temática de Comunicação, Articulação e Mobilização e Comissão Temática de Gerenciamento do Fundo de Assistência Social (CIPEC, 2002).

Lavalle, Houtzager e Castello (2006) elaboram um texto que tem como objetivo discutir a questão da representatividade política nos espaços participativos, e alguns resultados desta discussão auxiliam na construção da democracia. O Brasil tem se tornado referência para os países estrangeiros pelas suas experiências de participação na construção da democracia. Para os autores, isso jamais havia acontecido, pois em todas as épocas o Brasil era influenciado por outros países em quase tudo o que fazia. Os autores acreditam que isso está relacionado ao protagonismo da Sociedade Civil na busca pela consolidação da democracia através da participação e controle das ações do Estado, uma vez que a democracia cria espaços favoráveis para isso. Dessa maneira, os Conselhos são espaços de representação política, ou seja, os conseIheiros representam determinados segmentos. "Representar significa 'fazer as vezes do outro' ou 'estar no lugar do outro' em um determinado momento ou espaço" (DOWBOR, 2008, p. 13). Essa representação nos espaços participativos refere-se sempre à defesa de interesses coletivos. Por exemplo, os usuários representam os interesses de todos eles, assim como os trabaIhadores ou entidades. Logicamente que pode haver discrepâncias nessa relação uma vez que os sujeitos, segundo Dagnino (2002), podem estar participando motivados pela busca de interesses particulares. São desafios que os conselheiros precisam superar, na perspectiva de construir uma representação legítima e democrática. Vale lembrar que a escassez do tempo também é um desafio para os representantes, pois eles têm atividades pessoais e/ou profissionais que, na

316 Emancipação, Ponta Grossa, 14(2): 303-320, 2014. Disponível em <http://www.revistas2.uepg.br/index.php/emancipacao> 
maioria das vezes, são em outros espaços e requer destes constante presença. O Conselho tem diversidade de atividades e isso exige dos conselheiros tempo e disponibilidade para o estudo de documentos e legislação para que possam acompanhar o andamento da política.

Uma representação pode ser efetiva quando o representante busca informação a respeito das necessidades e interesses do coletivo que ele representa. Essa é uma prática pouco comum nos Conselhos de política. Muitas vezes o conselheiro não se lembra sempre de quem ele está representando e isso fortalece os interesses particulares. É uma forma de prestar contas aos sujeitos representados (DOWBOR, 2008). Diante disso, a autora faz um alerta interessante: "O papel do representante é agir em benefício dos interesses dos representados, mas isto não quer dizer que é necessário cair no particularismo. $O$ representante deve defender os interesses do seu segmento sem deixar de reconhecer as necessidades e demandas de outros segmentos" (DOWBOR, 2008, p. 19). Mas, Lavalle, Houtzager e Castello (2006, p. 46), alertam para a existência dificuldades no quer se refere à representação de interesses coletivos nos espaços participativos, que é a "[...] separação entre representante e representado [...]" que é próprio da forma de democracia na era moderna. $O$ fato de um sujeito estar participando para representar interesses coletivos não significa que ele o faça na efetividade. $E$ mais, nos Conselhos de política é comum que pessoas diretamente ligadas a entidades estejam participando dos Conselhos em nome dos usuários. Isso é definido por Dagnino (2002) como representação não legítima, ou seja, existe uma sub-representação. Segundo Lavalle, Houtzager e Castello (2006), normalmente isso acontece quando se refere à representatividade dos usuários. Os autores apontam que existem três elementos de conjugação da representação, sendo o representado ${ }^{25}$, o representante ${ }^{26}$ e o lócus ${ }^{27}$.

\footnotetext{
25 "[...] pessoa cuja vontade se consubstancia de maneira em maior ou menor grau direta e concreta (voto, reclamo, petição), ou de maneira necessariamente indireta e abstrata (nação, tradição, bem comum) [...]".

26 "[...] intermediário e guardião dos interesses do representado, cujo papel descansa em graus diversos de institucionalização, de autorização e de obrigatoriedade para com os representados [...]"

27 “[...] a um só tempo instância onde a representação é exercida e
}

Nestes casos, o representado seria o usuário dos serviços, o representante aquele que faz a intermediação entre o governo e os interesses do representado e o lócus "[...] se concentra no poder público e, com menor frequência, em outras instâncias e perante outros interlocutores societários" (LAVALLE, HOUTZAGER e CASTELLO, 2006, p. 50).

\section{Considerações finais}

A descentralização político-administrativa na Política de Assistência Social está sendo implementada através da territorialização dos serviços socioassistenciais prestados através do equipamento dos Centros de Referência de Assistência Social (CRAS) e Centro de Referência Especializado da Assistência Social (CREAS). Considera-se relevante que os municípios preocupem-se em levar os serviços para perto da população atendida, no entanto, faz-se necessário uma gestão democrática e competente para levar ao território descoberto e vulnerabilizado também os recursos de infraestrutura, além dos serviços socioassistenciais para que não a territorialização não passe a funcionar como um meio para retirar as pessoas que vivem em situação de pobreza dos espaços urbanos, escondendo-as em seus próprios territórios. Descentralizar é diferente de municipalizar. Portanto, há que haver contrapartida entre as três esferas de governo, e principalmente, como defendem os autores estudados, há que haver o compartilhamento do poder, inclusive, do poder de decisão entre eles. É precisa pensar no território como o espaço foco de transformação por parte do estado.

Para que isso possa acontecer, o financiamento é parte fundamental da empreitada governamental para que possa garantir os direitos sociais. Ele é um recurso destinado para a política e alocado no Fundo de Assistência Social (FAS), no qual os cidadãos podem fazer o controle de seu gasto, assim como da prestação de contas. É importante que os conselhos de Assistência Social garantam que os recursos sejam alocados no FAZ e que os conselheiros possam controlar os gastos. E também, que as prefeituras tenham um percentual de recursos garantidos e destinados

interlocutores perante os quais se exerce - notadamente o poder público, mas não só [...]". 
mensalmente para a política, funcionando como contrapartida aos recursos estaduais e federais.

Além dele, faz parte de uma gestão competente que possui a lógica do direito social, a Política de Recursos Humanos, a qual propõe a valorização e o respeito para com os seus trabalhadores. É também uma questão de garantir direitos àqueles que trabalham para garanti-los para os demais de sua classe. A viabilidade de planos de carreiras, cargos e salários e contratação via concurso público são apenas algumas de suas pautas.

A Matricialidade sócio familiar, que coloca a família como centro da atenção das ações dos CRAS e CREAS, é uma tendência das políticas públicas desde a introdução do ideário neoliberal na gestão pública. É necessário ampliar a atenção para além da família, para não correr o risco de retornar às ações focalistas historicamente construídas na assistência social. É preciso entender o sujeito coletivo representado na família como parte integrante de um sistema de classes sociais antagônicas e sujeitas a exclusão social e à pobreza decorrente do sistema de organização da sociedade - o sistema capitalista. No espaço territorial das famílias está uma comunidade, uma parte da classe trabalhadora, seus sonhos, suas utopias, suas esperanças e sua marginalidade. Fortalecer os espaços democráticos, as organizações comunitárias, os Movimentos Sociais, a luta dos trabalhadores, e ampliar a visão crítica destes sujeitos é também tarefa dos trabalhadores do Sistema Único de Assistência Social (SUAS).

Outro aspecto importante a ser fortalecido é a participação popular nos espaços dos conseIhos que ainda é um desafio a ser enfrentado na política, mas é construção e aprendizado. Faz-se necessário a coletiva construção de uma efetiva representação dos segmentos nos espaços de participação. Somente dessa maneira, lembra Couto (2008), podemos romper com os estigmas históricos de uma assistência social baseada no favor e na tutela, pois direito e assistência social só serão compatíveis quando a Sociedade Civil se apoderar dos canais de participação e controle social e obrigar o Estado a efetivar os direitos legalmente constituídos.

Para que tudo isso possa ser efetivado, a informação, o monitoramento e a avaliação são fundamentais, pois fazem parte da gestão da política. O planejamento das ações a curto, médio e longo prazo, mediante diagnóstico permanente da realidade dos territórios, contribuem para que se possa ir para além das ações emergências. A informação é fundamental para que os cidadãos de forma geral possam exercer o controle social dos serviços. A PNAS prevê a vigilância social da realidade sempre em movimento nos territórios para que se possa sistematizar informações e produzir indicadores para possibilitar maior aproximação dos riscos e vulnerabilidades da classe trabalhadora. Portanto, a gestão do SUAS em acordo com as normativas legais pode produzir o efeito de romper com os estigmas conservadores, históricos na Política de Assistência Social, e construir uma política de fato pública, direito do cidadão e dever do Estado.

\section{Referências}

ASSUMPÇÃO, Márcio José. Contabilidade pública. Curitiba: IBPEX, 2007;

AVELAR, Lúcia. Participação política. In.: AVELAR, Lucia \& CINTRA, Antonio Octavio (org). Sistema Político Brasileiro: uma introdução. Rio de Janeiro: Fundação Konrad-Adenauer-Stiftung; São Paulo: Fundação Unesp, 2004;

BERNARDONI, Doralice Lopes. Planejamento e orçamento na administração pública. $2^{\mathrm{a}} \mathrm{Ed}-$ Curitiba: IBPEX, 2010;

BRASIL. República Federativa. Constituição Federativa do Brasil. Brasília-DF: Senado, 1988;

Senado, 2000;

Lei complementar $n^{\circ}$ 101. Brasília-DF:

Projeto de Lei 3.077. Brasília-DF, 2008;

Lei $n^{\circ} 12.101$ de 27 de novembro que dispõe sobre a certificação de entidades. Brasília DF, 2009;

Resolução $n^{\circ} 16$ de 05 de maio que define os parâmetros nacionais para a inscrição de entidades. Brasília DF, 2010;

Lei $n^{\circ} 12.435$ dispõe sobre a Organização da Assistência Social. Brasília-DF, 2011;

CARVALHO, Maria do Carmo Brant de. Avaliação de projetos sociais. In.: AVILA, Célia M. de. Gestão de projetos sociais. $3^{a} \mathrm{Ed}-$ São Paulo: Associação de Apoio ao Programa Capacitação Solidária (AAPCS), 2001; 
A gestão do Sistema Único de Assistência Social (SUAS): uma discussão sobre os eixos ...

CFESS, Conselho Federal de Serviço Social. Parâmetro para atuação de assistentes sociais e psicólogos (as) na Política de Assistência Social. Brasília, CFP/CFESS, 2007;

CIPEC, Centro Interdisciplinar de Pesquisa e Consultoria em Políticas Públicas. Estado e Política Pública de Assistência Social, Sistema Descentralizado e Participativo de Assistência Social e Redes - (V. I) - Curitiba: Cipec, 2002;

DAGNINO, Evelina. Sociedade Civil, Espaços Públicos e a Construção Democrática no Brasil. In.: DAGNINO, Evelina. Sociedade Civil e espaços públicos no Brasil. São Paulo: Paz e Terra, 2002;

DOWBOR, Monika (Org).Enfrentando os desafios da representação em espaços participativos. São Paulo: CEBRAP: IDS, 2008;

HOROCHVSKI, Rodrigo Rossi e MEIRELLES, Giselle. Problematizando o conceito do empoderamento. In.: Anais do II Seminário Nacional Movimentos Sociais, Participação e Democracia (NPMS ISSN 1982-4602) Florianópolis, 2007;

LAVALLE, Adrián Gurza; HOUTZAGER, Peter P. e CASTELLO, Graziela. Representação política e organizações civis: Novas instâncias de mediação e os desafios da legitimidade. In.: Revista Brasileira de Ciências Sociais (V. 21 NN$^{\circ}$ 60). São Paulo: RBCS, 2006;

LIMA, Telma Cristiane Sasso de e MIOTO, Regina Célia Tamaso. Procedimentos metodológicos na construção do conhecimento científico: a pesquisa bibliográfica. In.:Revista Katálysis. V. 10 - Florianópolis, 2007. Disponível em http://www.scielo.br . Acesso em 05/10/09;

LOAS, Lei Orgânica de Assistência Social. República Federativa do Brasil. Brasília - DF, 1993;

MDS, Ministério do Desenvolvimento Social e Combate à Fome (MDS). Orientação Técnica para o Centro de Referência de Assistência Social (Versão preliminar) - Brasília, 2006;

MESTRINER, M. L. O Estado entre a filantropia e a assistência social. $2^{\mathrm{a}}$ ed. São Paulo: Cortez, 2001;

MOURA, Reidy Rolim de. Estruturas de oportunidades políticas e aprendizado democrático - 0 associativismo de Bairro em Blumenau (19942009). Tese de Doutorado defendida no Programa de Pós Graduação em Sociologia Política da Universidade Federal de Santa Catarina. Florianópolis, 2009;
NOB/SUAS, Norma Operacional do Sistema Único de Assistência Social. República Federativa do Brasil. Brasília - DF, 2005;

NOB/SUAS-RH, Norma Operacional Básica de Recursos Humanos. República Federativa do Brasil. Brasília - DF, 2007;

NOGUEIRA, Marco Aurélio. Um estado para a Sociedade Civil: temas éticos e políticos da gestão democrática. $2^{a}$ ed. São Paulo: Cortez, 2005;

PEREIRA, Potyara A. P. Necessidades humanas: subsídios à crítica dos mínimos sociais. São Paulo: Cortez, 1995;

Necessidades humanas: subsídios à crítica dos mínimos sociais. $5^{\mathrm{a}} \mathrm{Ed}$ - São Paulo: Cortez, 2008;

Mudanças estruturais, política social e papel da família: crítica ao pluralismo de bem-estar. In.: SALES, Mione Apolinário (et al). Política social, família e juventude: uma questão de direitos. $4^{\mathrm{a}}$ ed. São Paulo: Cortez, 2009;

PNAS, Política Nacional de Assistência Social. República Federativa do Brasil. Brasília - DF, 2004;

SARTI, Cyntia A. Famílias enredadas. In.: ACOSTA, Ana Rojas e VITALE, Maria Amália Faller (Orgs). Família: redes, laços e políticas públicas. $4^{a}$ ed. São Paulo Cortez, 2008;

SCHONS, Selma Maria. Assistência Social entre a ordem e a "des-ordem": mistificação dos direitos sociais e da cidadania. $2^{\mathrm{a}}$ ed. São Paulo: Cortez, 2003;

SETP, Secretaria de estado do Trabalho, Emprego e Promoção Social. Caderno SUAS II. Curitiba, 2007;

SEVERINO, Antônio Joaquim. Metodologia do trabalho científico. $23^{\mathrm{a}} \mathrm{Ed}$ - Revista e Atualizada. São Paulo: Cortez, 2007;

SUAS, Sistema Único de Assistência Social. MPAS, Brasília - DF: 2005;

SUAS/PR, Sistema Único de Assistência Social. Sistema Municipal e Gestão Local do CRAS Caderno I e II - Curitiba, 2006;

SUAS/PR, Sistema Único de Assistência Social. Centro de Referência Especializado de Assistência Social - Caderno SUAS I: Assistência Social Sistema Municipal e gestão local do CREAS - (Guia de Orientação I). Curitiba, 2006; 
SIQUEIRA, Rosângela Bujokas de. Conselhos de política e participação democrática: análise dos setores saúde e assistência social em Ponta Grossa - PR. Dissertação de mestrado defendida no Programa de Mestrado em Ciências Sociais Aplicadas da Universidade Estadual de Ponta Grossa (UEPG). Ponta Grossa: UEPG, 2006;

SOUZA, Rodriane de Oliveira. Participação e controle social. In.: SALES, Mione Apolinário (et al). Política Social, Família e Juventude: uma questão de direitos. $4^{\mathrm{a}}$ Ed - São Paulo: Cortez, 2009;

SPOSATI, Aldaíza de Oliveira (et al). Assistência na trajetória das Políticas Sociais brasileiras: uma questão de análise. $6^{a}$ ed. São Paulo: Cortez 1995;

Mínimos sociais e seguridade social: uma revolução da consciência da cidadania. In.: Serviço Social \& Sociedade ( $n^{\circ} 55$ - ANO XVIII - Novembro). São Paulo: Cortez, 1997;

TAPAJÓS, Luziele. A Gestão da Informação em Assistência Social. In.: Curso de Formação de Gerentes Sociais realizado no Programa Gestão Social com Qualidade pela Escola Nacional de Administração Pública (ENAP). Londrina, 2008;

TATAGIBA, Luciana. Os conselhos gestores e a democratização das políticas públicas no Brasil. In.: DAGNINO, Evelina. Sociedade Civil e espaços públicos no Brasil. São Paulo: Paz e Terra, 2002;

TCU, Tribunal de Contas da União. Orientações para Conselhos da Área de Assistência Social. $2^{\text {a }}$ Ed - Brasília, 2009;

YAZBEK, Maria Carmelita. Classes subalternas e assistência social. $4^{\text {a }}$ ed. São Paulo: Cortez, 2003. 